\title{
RECEIVING TRAINING TO TEACH THE 'PROHIBITED \\ LANGUAGE: THE ATTITUDE OF STUDENT TEACHERS \\ MAJORING IN A GHANAIAN LANGUAGE (AKAN) IN THE \\ COLLEGES OF EDUCATION IN GHANA
}

\author{
Abdulai Akuamah - Faustina Gyampoh - Leticia Asamoah
}

doi: 10.18355/PG.2022.11.1.9

\begin{abstract}
Lecturers, teachers, and students often consider students majoring in indigenous languages in Ghana as academically weak. However, some students still pursue it as a major in the Colleges of Education in Ghana. The present study investigates the attitude of student teachers majoring in an indigenous language Akan in the Colleges of Education in Ghana. To do so, three colleges, namely, St. Joseph's College of Education, Abetifi Presbyterian College of Education, and Fosu College of Education, were purposefully selected. A total of 212 students comprising 101 males and 111 females were recruited for the study. The data were quantitatively analyzed. The results showed that most participants have a positive attitude toward the study of Akan in general at the College of Education level.

Similarly, student teachers' attitude toward majoring in Akan was positive since the overwhelming majority are not perturbed by the stigma associated with studying the Akan language in general. Finally, although a slight majority believed that they would allow their loved ones to pursue Akan in the future, other responses indicated participants had diverse opinions. This attitude will go a long way to change the negative perceptions others have about the study of indigenous languages in Ghana.
\end{abstract}

\section{Key words}

Ghanaian Language, Akan, Language Policy, Language Attitude, Colleges of Education, Student teachers, indigenous languages

\section{Introduction}

Language attitude plays an integral role in language learning. It is important in the language policy in multilingual societies. Wamalwa (2013) opines that people who live in monolingual communities tend to have one attitude toward the language they speak since they have no other language to compare theirs with. On the contrary, Owu-Ewie and Edu-Buandoh (2014) noted that the situation differs in a bilingual or multilingual society since there is a tendency to develop different attitudes towards the various languages. In Omoniyi (2014), the attitude according to a language, either positive or negative, depends on the socio-economic value attached to each language. It must also be noted that attitudes being positive or negative, have a strong impact on language learning success (Getie, 2020).

Unfortunately, the study of indigenous languages in schools in SubSahara Africa has been greeted with negative attitudes because it has not been given the needed attention by the various governments and other 
relevant stakeholders in education. This is because most of these countries have adopted their colonial masters' languages as their official languages. They are the languages used in education, governmental business, administration, printing, and distribution of laws, and professional businesses and commerce. According to Ramachandran and Rauh, Christopher (2016), this appears to have conditioned citizens in these countries to develop an insatiable appetite for the colonial masters' languages at the expense of the indigenous African languages. In addition to this, Albaugh (2014) observes that no single country in Sub-Sahara Africa provides secondary or tertiary education in the local languages. Thus far, only two countries, namely Tanzania and Ethiopia, run their primary school education in their local languages. Even in South Africa, where eleven (11) indigenous languages have been given official status, it is not left off the tenterhook. The implementation remains a huge challenge due to a lack of political will. Kretzer (2016) partly attributes the political unwillingness that English, the preferred language, is an indicator of being educated and part of the elite class. Thus, the English language has received functional and prestigious status resulting in the populace developing a positive attitude toward it while the indigenous languages on the other side have been accorded negative attitudes and subsequently relegated to the background.

Since Ghana was the first country in Sub Sahara Africa to gain independence from its colonial masters under the leadership of Dr. Kwame Nkrumah, a staunch Pan-Africanist, one would expect that its linguistics orientation will differ immensely in terms of attitudes towards the indigenous languages. However, that has not been and is not the case either. English is the official language and the language used in education. One's progress in education from one level to another is dependent on a pass in the English language examination. Thus, the progression from Senior High School to the tertiary level is determined by a credit pass in English. This requirement put English on a higher pedestal and was considered the only language worthy of being literate. Students and teachers who speak fluent English are respected and considered brilliant. What makes it more interesting is that the academic credence of a school is determined by the ability of the students to speak impeccable English.

On the contrary, the Ghanaian languages have unfavorable negative attitudes (Owu-Ewie \& Edu-Buandoh, 2014). They are described with a derogatory terminology vernacular. All punishments are meted out to students who speak their native language in schools. According to Guerini (2008) and Bamgbose (1991), teachers, lecturers, and students looked down upon and tagged students who studied their indigenous as academically weak. They are perceived as underachievers who go for the easy options to make good grades. These, coupled with other factors, make the teaching and learning of the subject unattractive to the up-and-coming students.

Consequently, parents do not encourage their children to pursue it at the senior high school level. Most of the few who pursue the Ghanaian Language also owe to the stigmatization suffered at the previous stages of their education shy away from pursuing it to the tertiary level. Nonetheless, 
some students defy these odds not just aspiring to pursue it as a program at the College of Education but to teach the unfavoured 'prohibited' languagesomething they will be doing in their lifetime. Therefore, it is imperative to determine what motivates their decision to learn the native language in tertiary by asking What are the attitudes of student teachers majoring in Akan towards the study of Ghanaian Language as a general course in the Colleges of Education? What are the attitudes of student teachers pursuing Akan as a major program in the Colleges of Education towards the program? What are student teachers' attitudes regarding the future of Akan as a program of study?

Agyekum (2020) defines 'Akan' as referring to both the people and their language. The Akans are ethnographically distinct from the Ahantas, Aohwins, Nzemas, and Sefwis. Akan is a native language spoken by Akans. They are Ghana's largest ethnic group. According to the 2010 national population and housing census, Akan is spoken natively by $47.5 \%$ of Ghana's population, while $44 \%$ of non-Akans do. At Cote d'Ivoire, Akan is also spoken. It is, without a doubt, the dominant language used in Ghana's electronic media (radio and television) stations. ). It is worth noting that, while Akan is studied from primary school to tertiary level education in Ghana, it lacks a common orthography. However, the three dialects of Asante, Akuapem, and Fante have been reduced to writing and are taught in schools as Akan, depending on the school or region in which one resides.

\section{Literature review}

\section{Indigenous Languages in Ghana's Language Policy}

Ghana practices an early-exit transitional type of bilingual education (OwuEwie, 2019). This model starts with the Ghanaian language as a medium of instruction and later replaces it with English. The two languages involved are overtly stated in the curriculum to avoid conflict. Ghana's language policy in education indicates that the medium of instruction from Kindergarten 1-2 and Grade/Basic 1-3 should be in one of the eleven indigenous languages (Akuapem Twi, Asante Twi, Dagaare, Dagbani, Dangme, Ewe, Fante, Ga, Gonja, Kasem, and Nzema) that have to acquire literacy status and are the predominant Ghanaian languages in the school community. At the same time, English is taught as a subject. Under the current educational reforms where the premium is placed on Reading, Writing, Arithmetic, and Creativity, it is clearly stated that "fifteen periods have been allocated to language and literacy (English and Ghanaian language) per week. Language and Literacy should therefore be assigned three periods a day." (NaCCA - Teacher Resource: p.15, 2019).

The transition to English as the medium of instruction occurs in Basic 4 upward, while the Ghanaian language is taught as a compulsory subject through Junior High School to the first year in the Senior High School (SHS 1, now BS11). The Ghanaian language is taught as an elective subject from SHS 2-3 (SHS 1, now BS12 and BS 13, respectively). All national examinations, except for the Ghanaian language subject exams, are conducted in English. 
Ghanaian language is currently a required subject for all student teachers enrolled in Ghana's education colleges preparing to teach in the early grades and primary levels. Once again, Colleges affiliated with the University of Cape Coast require all first-year student-teachers pursuing a Bachelor of Education in Junior High School Education to take a course in a Ghanaian language, regardless of the subject area. However, only students pursuing a Bachelor of Education in English/Ghanaian Language at colleges affiliated with the amalgamated universities (Kwame Nkrumah University of Science and Technology, University of Ghana, University of Education, Winneba, and University for Development Studies) study Ghanaian. The University of Ghana, the University of Education, Winneba, and the University of Cape Coast all offer Ghanaian-language Bachelor of Arts (BA) or Bachelor of Education (BEd), Master of Arts (MA), and Master of Philosophy (MPhil) degrees. Only ten of Ghana's more than forty-six languages are studied at the tertiary level. Akan, Ewe, Ga, Gurune, Sissala, Nzema, Gonja, Kasem, Dagaare, and Dagbani are among these languages. In comparison to English, these programs attract a small number of students.

\section{Language Attitude}

From a psychological standpoint, an attitude is a mental state of readiness that reacts to something based on prior experiences and influences behavior toward a specific object (Navarro-villarroel, 2011). Additionally, according to Bartram (2010), attitude is "a mental and neural state of readiness that is organized through experience and exerts a directive or dynamic influence on the individual's response to all subjects and situations with which it is associated." Thus, from the mentalist's perspective, attitude can be defined as a state of mind. From a behaviorist perspective, Fishbein and Ajzen $(1975 ; 2000)$ define attitude as a learner's proclivity to respond consistently favorably or negatively to a given object. This means that attitude is acquired through an individual's interactions with their environment. As a result, attitudes are not fixed; they constantly fluctuate and shift in response to the social environment (Wamalwa, 2013). Gok and Silay (2010), in a related study, define attitude as a mental concept that expresses favorable or unfavorable feelings toward an object. To this end, both psychologists and behaviorists agree that no one is born with attitudes; rather, they are acquired through socialization.

On the other hand, Bohner and Wanke (2002) believe that attitudes can be inherited. Meanwhile, Garder (1985) takes a contrary position, claiming that attitudes are acquired, not inherited or genetically endowed. Psychologists categorize attitude into affective, behavioral, and cognitive components (Monar, Lopez, Altamirano, \& Villa, 2018). McLeod (2014) postulates that a stronger attitude often affects behavior. Salta and Tzougraki (2004) state that the affective component refers to the feeling about the object, while behavioral attitude refers to how people act toward an object. The cognitive is also considered the "component that pertains to opinions, beliefs, and knowledge regarding a particular language and its usage within particular contexts." (Seti \& Bornman, 2015). 
According to Sanusi (2018, p.130), language attitude is "a sociolinguistic terminology that refers to the feelings that people have about their language or the language(s) of other people." As pointed out by Kadodo et al. (2012), attitude can be positive, negative, or in some rare cases neutral. This means that language learners' attitudes have a great impact on both "the language learning process and the learning outcome." (Tódor \& Dégi 2016, p.123). The successful teaching or learning of a language depends on the learner's attitude toward the language. The implication is that teachers and learners with a positive attitude towards a language will tend to put in every effort possible to learn that language. Intrinsically, learners will be motivated to invest reasonable time and resources to progress steadily towards the target language (Kadodo et al., 2012). On the other hand, a negative attitude will make teachers and learners "give up and feel that the teaching and learning of such language is an unnecessary bother" (Kadodo \& Muzira, 2019).

\subsection{Attitude towards Indigenous Language in Education}

According to Baker (1992), there is a strong correlation between language attitude and education since education is believed to play an integral role in shaping language attitude and imparting the outcome of language maintenance and language shift process, especially, countries with no clear language policy but relay on the educational language of the country as the national language policy. The importance of language attitude in educational language policy is also highlighted by studies like Edwards (1994), Heugh (2000), Sarfo (2012), Owu-Ewie and Edu-Buandoh (2014), and Aboagye and Adade-Yeboah (2019).

Studies have shown that learning in the mother tongue effectively improves knowledge and concepts, permanent reading habits, and critical thinking skills (Eğitim-Sen, 2005; Michou, Mouratidis, Ersoy, \& Uğur, 2016). Aydin and Dogan (2019) conducted a study to examine the attitude of teachers toward mother tongue-based multilingual education in Turkey to find out how teachers within the public schools perceive multilingual education. The study showed that teachers have a positive attitude toward the mother tongue-based policy. In a study about "Attitudes of Arabic- and Non-Arabic Speaking Parents toward the Importance of Learning Arabic in the United States," Alili and Hassan (2017) investigated Arabic-speaking and NonArabic-speaking parents' attitudes and expectations the learning of Arabic by their children in schools. The researchers concluded that parental attitude to the learning of Arabic was positive. They believe Arabic will help their children to maintain their culture, religion, traditions, and cultural heritage in the United States of America.

On the contrary, a similar study conducted by Sanusi (2018) revealed that the Nigerian Education system views the "indigenous language as a 'weed' with the contending plant (i.e. English)." Teachers, parents, students, and other stakeholders have a negative attitude toward using indigenous language in the school setting and therefore consider using the indigenous Nigerian languages as a hindrance to students' performance in English. Ramachandra and Christopher (2016) also conducted a study to analyse which channels influence individual preferences concerning the 
choice of the official language in Zambia. They discovered that people's preference for the indigenous language as a medium of instruction in schools and the official language was low. The study showed that the individuals conflate knowledge with the medium through which the knowledge is transmitted and therefore favour English at the expense of their language. This study is not different from Khejeri's (2014), where he examined teachers' attitudes towards teaching and using Mother Tongue as the medium of instruction at the lower primary in Hamis District in Western Kenya, East Tiriki Division. The study revealed that Mother Tongue is less valued than English.

No wonder Adegbija (1994) describes the negative attitude towards the local languages in the educational settings in Africa as glaring. The reason is that, in most African countries, there are no overt language policies apart from what is being implemented in the educational sectors. Owu-Ewie and Edu-Buandoh (2014) point out that the English language is highly favoured in post-Junior High School, which is no different in Ghana. Despite Ghana being a multilingual country, education is run using English which is the language of the colonial masters, at the expense of the local languages. This has led to the perception held by many as English being "the only language worth being literate in or even the sole language worth investing in, to the detriment of local languages" (Owu-Ewie \& Bannor, 2014, p.7).

Few studies have been conducted in Ghana to ascertain attitudes toward the use of language in education. These studies generally reveal a negative attitude toward using indigenous languages in education as a medium of instruction and a subject of study. In a study conducted by Amissah et al. (2001) in six primary schools and six Teacher Training Colleges (now Colleges of Education) to assess the implementation of Ghana's educational language policy, it was discovered that parents and students had a favourable attitude toward the use of English as a medium of instruction, while their attitudes toward the use of the Ghanaian language as a medium of instruction were negative. Again, the study revealed that, while pupils comprehend better when their teachers teach them in Ghanaian, they prefer their teachers to teach them in English in order to become fluent in the language. Additionally, the study revealed that some teachers who teach other languages preferred English as the medium of instruction over the Ghanaian language. They believed that using the Ghanaian language as a medium of instruction slowed the study of English and harmed academic excellence at the same time. Kwofie (2001) compared students' attitudes toward English, Pidgin, and Ghanaian. He discovered that students have a negative perception of Ghanaian languages but a positive perception of English.

Owu-Ewie and Edu-Buandoh (2014) conducted a study to ascertain students' attitudes toward learning the Ghanaian language in Senior High School (SHS). Eleven (11) Ghanaian language teachers and 110 students from eleven (11) secondary schools located throughout Ghana's Central and Western regions. The study discovered that parents, school officials, other language teachers and students, and the general public all have negative 
attitudes toward Ghanaian language study at the secondary school level. Their actions and inactions reflect their negative attitudes. These individuals' negative attitudes have had a detrimental effect on the number of students enrolling in schools to study Ghanaian languages and the morale of both teachers and students of Ghanaian languages. For example, teachers, lecturers, and students regarded students studying the Ghanaian language with contempt and labelled them academically illiterate.

Additionally, they regard them as outmoded due to their status as 'local teachers.' After all, they teach a language that is only spoken in their immediate vicinity and thus cannot be taught in other countries. In the same study, L1 teachers were defined as incapable of teaching anything other than the Ghanaian language. Again, both L1 students were labelled as being unable to communicate in English. One fascinating finding is that most Ghanaian language teachers surveyed do not wish to pursue graduate studies in the Ghanaian language. They were more interested in teaching English as a Second Language than teaching English as a First Language because they were tired of the stigma and desired to avoid it.

Additionally, the students stated that the stigma prevents them from studying the Ghanaian language. The study further revealed that students studying the Ghanaian language were considered as not being intelligent. Andoh-Kumi (1997, p. 49) also highlighted the seriousness of the stigmatisation in Ghana in the excerpt below:

[Pupils] have very high respect and admiration for teachers and other people who can express themselves fluently in English. Even teachers have great respect for their colleagues in the English departments and those who are very proficient in English. [...] Some parents are disappointed when they learn that their children or wards learn their native languages at school. It is common to hear such comments/ questions as: 'why should we pay high school fees only for you to learn languages we already speak?.

A comment like this makes the teaching and the learning of the Ghanaian languages unattractive to both teachers and learners. Both the school and the home environments do not favour the indigenous languages in Ghana. Teachers of the Ghanaian languages are not accorded much respect. Parents are not also happy when they learn their children are pursuing it as a program in school. Even teachers who teach the indigenous languages at a higher level, as indicated earlier, are considered not to be academically proficient compared to teachers who teach other subjects.

Similarly, a considerable proportion of students who study the Ghanaian language in senior high schools do not wish to continue studying it in university or teach it in teacher training institutions. The circumstances outlined in previous studies complicate the teaching and learning of indigenous languages in Ghana. Additionally, factors such as the growing process of internationalisation and globalisation place intense pressure on all of the country's indigenous languages. With the global adoption of English as a language of economy, education, commerce, and media, educators' language practises and attitudes toward language are impacted (Kretzer, 2016).

This means that the success or failure of Ghanaian language teaching and 
learning in Ghana's colleges of education is contingent on the learners' attitudes. This study is significant because it is directed at students who, despite the odds, have chosen not only to study the Ghanaian language at the tertiary level but also to teach it as a subject. At this point, it is clear that the attitude of students pursuing/majoring in Ghanaian Language (Akan) to teach it in primary schools, where these negative attitudes are still prevalent, has not been addressed. This is the void in the literature that this study seeks to fill by examining these students' attitudes toward indigenous language study.

\section{Purpose of the study}

The purpose of the present study is to investigate the attitude of student teachers pursuing Akan as their major programme at the colleges of education in Ghana. We also sought find out the students' attitude toward Akan as a subject of study and its future as well.

\section{Method}

This research is quantitative. This approach was used to reduce bias and facilitate the generalisation of data (Larson-Hall, 2016).

\section{Participants}

A total of two hundred and twelve (212) participants comprising 101 males and 111 females who major in Akan were used for the study. They were all first, second, and third-year students. Fourth-year students are not part of the study because there are currently no fourth-year students in the Colleges of Education -the students for the current program are in their third year second semester. The study was conducted in the second semester of the 2020/2021 academic year. The participants were student teachers of St. Joseph's College of Education, Bechem, Abetifi Presbyterian College of Education, Abetifi and Fosu College of Education, Fosu in the Ahafo, Eastern and Central regions of Ghana because Akan is respectively. 212 major students were purposively selected for the study since they possessed the information elicited for the study. According to David and Sutton (2009), in purposive sampling, the units are selected based on the researcher's knowledge and opinion about which ones they think will be appropriate to the topic area. However, out of the number, 212 students responded to the questionnaires. See Table 1 for participants' details.

Table 1: Demographics of the participants from the Colleges of Education in Ghana 


\begin{tabular}{|c|c|c|c|c|c|c|c|}
\hline \multirow[t]{2}{*}{ No. } & \multirow{2}{*}{$\begin{array}{l}\text { College } \\
\text { Education }\end{array}$} & \multicolumn{3}{|c|}{ Year } & \multicolumn{2}{|c|}{ Gender } & \multirow[t]{2}{*}{ Number } \\
\hline & & $1^{\text {st }}$ & $2^{\text {nd }}$ & $3^{\text {rd }}$ & Female & Male & \\
\hline 1 & St. Joseph's & 26 & 40 & 10 & 42 & 34 & 76 \\
\hline 2 & Abetifi Presbyterian & 14 & 23 & 24 & 34 & 27 & 61 \\
\hline 3 & Fosu & 23 & 45 & 7 & 35 & 40 & 75 \\
\hline Total & & 63 & 108 & 41 & 111 & 101 & 212 \\
\hline
\end{tabular}

\section{Instrumentation}

The questionnaires were designed using close-ended questions centered on experiences from previous research on language attitude. Again, apart from the data collection instrument's opinions, informal comments made by students during the discussion and the researcher's own experience of trying to find out students' attitude toward the study of Akan in Colleges of Education in Ghana. The researchers used this instrument because we wanted to cover a large number of the population. The researchers adapted a questionnaire comprising 11 items. Statements expressing certain degrees of positive or negative attitudes toward the study of Akan as a major programme were prepared. Participants evaluated each statement based on a five-point Likert scale; 'Strongly disagree,' 'Disagree, 'Uncertain,' 'Agree,' and 'Strongly Agree.'

\section{Data Collection Procedure}

The questionnaire was administered online using Google Form because of the COVID-19 pandemic because of the risk of paper and pen administration. Besides, the second-year students had virtual classes at the time. The study's objectives were explained to them through audio recordings posted on their various WhatsApp platforms. Participants were equally taken through how to fill the forms online since most of them were not familiar with the process. The participants selected options from the Likert scale that best describe their attitudes toward Akan as a major programme. The questionnaire was sent to all the target groups on their WhatsApp platforms. The setting was done to allow individuals to make one submission. This was to prevent one participant from submitting more than one form. The data from the questionnaire were analysed using descriptive statistics for the scores of mean, standard deviation, frequency, and percentage measures.

\section{Students Attitude towards the Study of Akan in Colleges of Education}

The questions in Table 2 were intended to determine the attitude of the student teachers majoring in Akan attitude towards the study of Akan in general. The question was a fashion to measure student's opinion on Akan as a course/program of study in general in the Colleges of Education in Ghana.

Table 2: Descriptive Statistics on Students Attitude towards the Study of Akan in Colleges of Education

Slavonic Pedagogical Studies Journal, eISSN 1339-9055, ISSN 1339-8660, Volume 11 Issue 1, 2022 


\begin{tabular}{llllll}
\hline Statement & Response & $\begin{array}{l}\text { Fr } \\
\text { eq } \\
\text { ue } \\
\text { nc }\end{array}$ & $\begin{array}{l}\text { Percentag } \\
\text { e }\end{array}$ & Mean & \\
& & \multicolumn{2}{c}{ SD } & \\
& & & & \\
& & 98 & 46.2 & & \\
1. Akan is the most & Strongly agree & 48 & 22.6 & & \\
interesting subject & Agree & 28 & 12.3 & & \\
that we have in the & Uncertain & 20 & 9.4 & & 1.343 \\
College $\quad$ of & Disagree & 20 & 9.4 & 1.13 & \\
Education. & Strongly Disagree & 212 & 100.0 & 1.13
\end{tabular}

\begin{tabular}{|c|c|c|c|c|c|}
\hline \multirow{6}{*}{$\begin{array}{l}\text { 2. I do not like } \\
\text { learning Akan } \\
\text { because it is not my } \\
\text { favourite subject. }\end{array}$} & Strongly agree & 24 & 11.3 & & \\
\hline & Agree & 12 & 5.7 & & \\
\hline & Uncertain & 17 & 8.0 & & \\
\hline & Disagree & 63 & 29.7 & & \\
\hline & Strongly & 96 & 45.3 & & \\
\hline & Disagree & 212 & 100.0 & 2.92 & 1.334 \\
\hline
\end{tabular}

\begin{tabular}{|c|c|c|c|c|c|}
\hline 3. I wish that no & Strongly agree & 29 & 13.7 & & \\
\hline subject in the college & Agree & 18 & 8.5 & & \\
\hline was taught in Akan. & Uncertain & 11 & 5.2 & & \\
\hline & Disagree & 44 & 20.8 & & \\
\hline & Strongly & 110 & 51.9 & & \\
\hline & Disagree Total & 212 & 100.0 & 2.89 & 1.462 \\
\hline
\end{tabular}

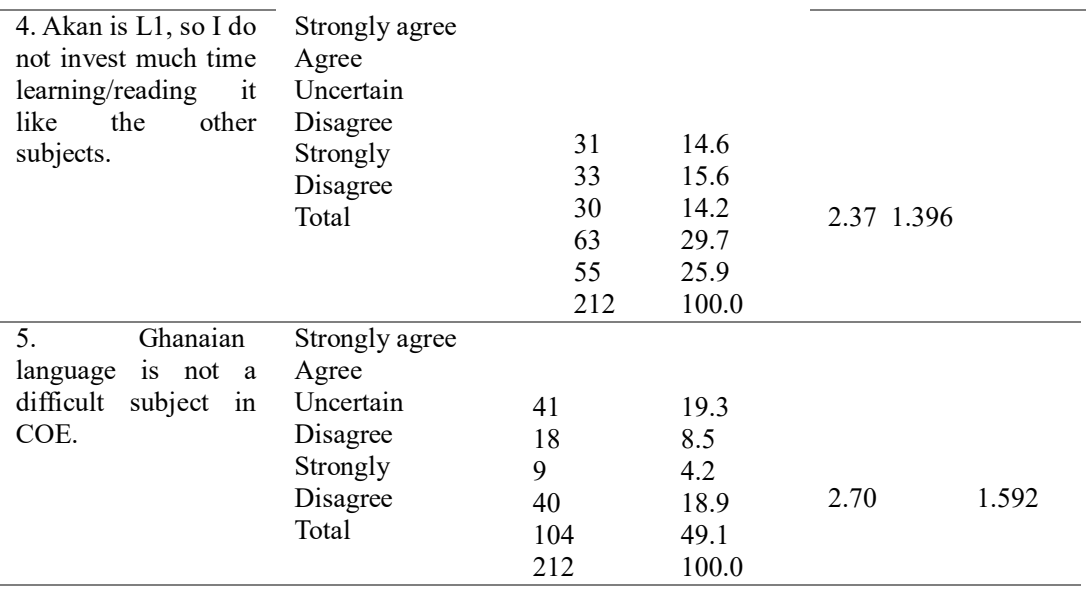

Table 2 depicts that most students teach $64.8 \%$ (i.e. 42.2 strongly agree and $22.6 \%$ agree) with the statement, Akan is the most interesting subject in the college of education. This means that $64.8 \%$ hold a positive attitude towards Akan as the most interesting course in the colleges of education. However, opposed to a good $18.8 \%$ (i.e., $9.4 \%$ strongly disagree and $9.4 \%$ disagree). 


\begin{tabular}{|c|c|c|c|c|c|}
\hline Statement & Response & Frequency & Percentage & Mean & SD \\
\hline $1 . \quad \mathrm{I}$ & Strongly agree & 38 & 17.9 & & \\
\hline have regretted & Agree & 7 & 3.3 & & \\
\hline for choosing & Uncertain & 12 & 5.7 & & \\
\hline Akan as a & Disagree & 16 & 7.5 & & \\
\hline programme at & Strongly Disagree & 139 & 65.6 & & \\
\hline $\begin{array}{l}\text { the College of } \\
\text { Education. }\end{array}$ & Total & 212 & 100.0 & $3.00 \quad .571$ & \\
\hline
\end{tabular}

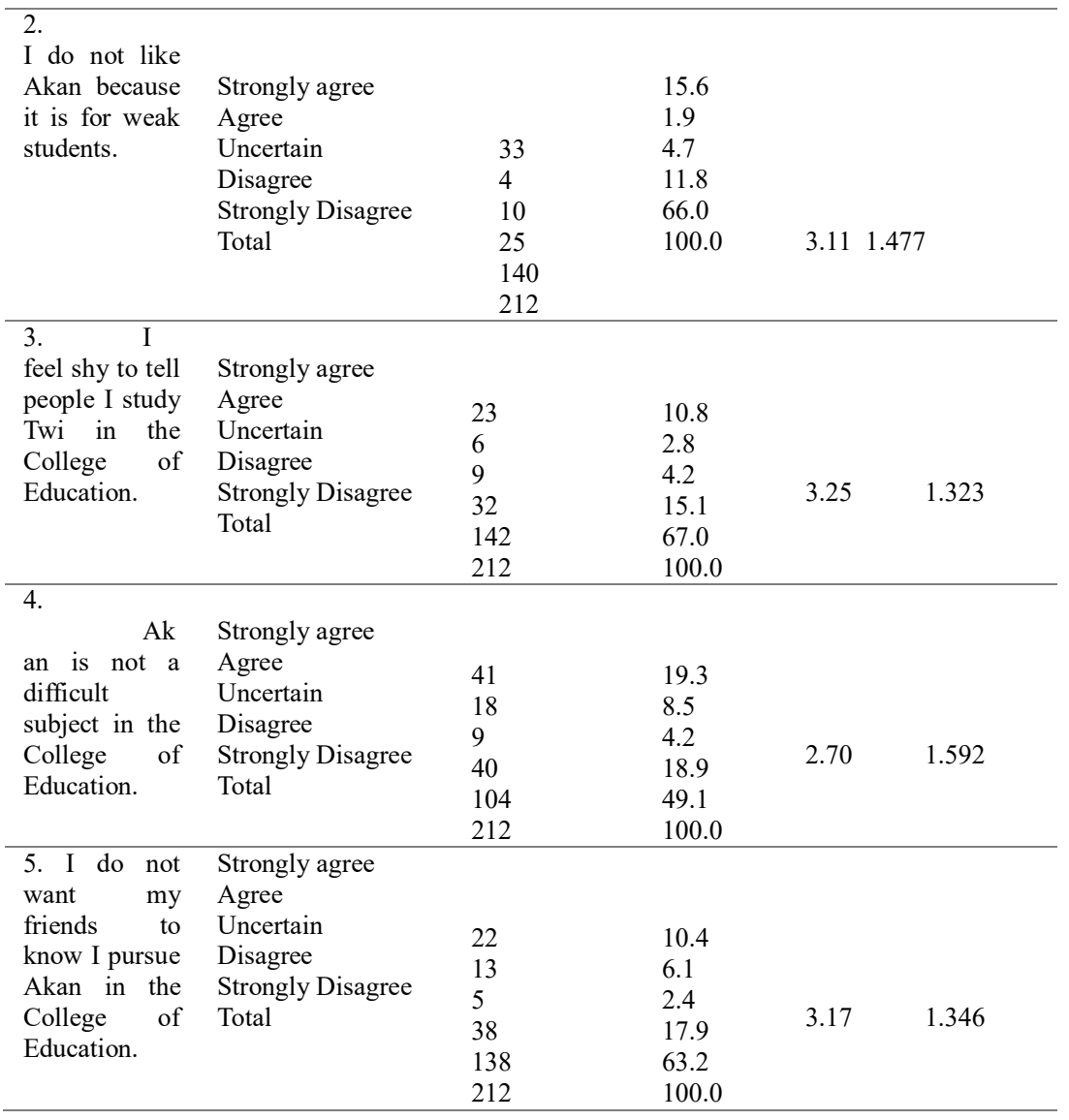

However, another $12.3 \%$ were uncertain about the statement.

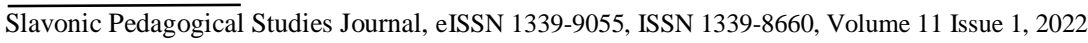


It is evident from Table 2 that participants $45.3 \%$ strongly disagree and $29.7 \%$ disagree with the statement, Akan is not my favourite subject in the college of education. Another $11.3 \%$ strongly agree, and $5.7 \%$ agree with the statement. Concerning this statement, the remaining $8.0 \%$ remained uncertain. This suggests that participants have a positive attitude forwards to the course that is taken in Akan.

Obviously, a strong majority (40\% strongly disagree and disagree) oppose the idea that no course should be taken in Akan in the colleges of education. On the other hand, 22.2\% (strong agree and agree) with the statement, and again just 5.2\% were uncertain. This means that participant's attitude forwards the study of Akan as a general course is positive.

Regarding the perceptions of the attitude of not investing much time in learning courses taught in Akan as against other courses, 55.6\% (i.e., 25.9\% Strongly disagree and $29.7 \%$ disagree) with another $30.2 \%$ (i.e., $14.6 \%$ strongly agree and $15.6 \%$ agree). Nevertheless, $14.2 \%$ of the participants remained uncertain.

Regarding Akan not being a difficult subject/course, 68\% (i.e., 49.1 strong disagree and 18.9 disagree) $27.8 \%$ (i.e., 19.3 strongly agree and 8.5 agree) with $4.2 \%$ uncertain about the statement.

\section{Students attitude towards the stigma Associated with Majoring in Akan}

The second domain of questions was designated to measure student teachers attitudes towards the stigma associated with the study of Akan at the tertiary level (COE); to a great extent, all the items show that participants attitudes towards Akan as a major program

Table 3: Descriptive Statistics on Students Attitude towards the Stigma Associated with Majoring in Akan

A significant majority of respondents (73.1\% strongly disagreed, $65.6 \%$ disagreed, and $7.5 \%$ disagreed) stated that they regretted majoring in Akan. Additionally, 5.7\% were unsure, while the remaining 21.2\% indicated strongly agreed, and 3.3\% indicated they regretted pursuing Akan.

As indicated in the preceding table (77.8\%), 66\% of participants strongly disagreed, and $11.8 \%$ disagreed that they major in Akan not because it is a subject for weak students. However, $4 \%$ were unsure. It is worth noting that $15.6 \%$ of respondents strongly agreed, with $1.9 \%$ stating that Akan is for weak students, which is why they study it.

Furthermore, $67 \%$ of the participants strongly disagreed that they feel shy to tell people that they pursue Akan in the college of education, and $15.1 \%$ disagreed with the statement, yet some participants disagreed $(10.8 \%)$ strongly agreed, and $2.8 \%$ disagreed with the statement. Here too, $4.2 \%$ remained uncertain. This means participants feel proud to let others offer Akan in the college of education. 
The table shows that $49.1 \%$ strongly disagreed that Akan is not difficult in the college of education and that $18.90 \%$ disagreed with the statement. On the other hand, $19.3 \%$ strongly agreed, and $8.5 \%$ also agreed with the statement. Yet, the remaining $4.2 \%$ of the participants were uncertain regarding the statement.

Again, $81.1 \%$ of the participant strongly disagreed $(63.2 \%)$ and disagreed $(17.9 \%)$ with the statement that they do not want their friends to know they are majoring in Akan in the college of education. Only 16.5\% of the participants strongly agreed (10.4\%) and agreed (6.1\%) with the statement. This implies that participants have positive self-esteem and are not boarded by what their friends think of them.

\section{Attitude regarding the study of Akan in the future}

This statement was intended to find out the future prospects as far as the study of Akan as a major program in the tertiary level is concerned. The results of the participants' responses are captured in Table 4 below.

Table 3: Descriptive Statistics on Attitude regarding the study of Akan in the Future

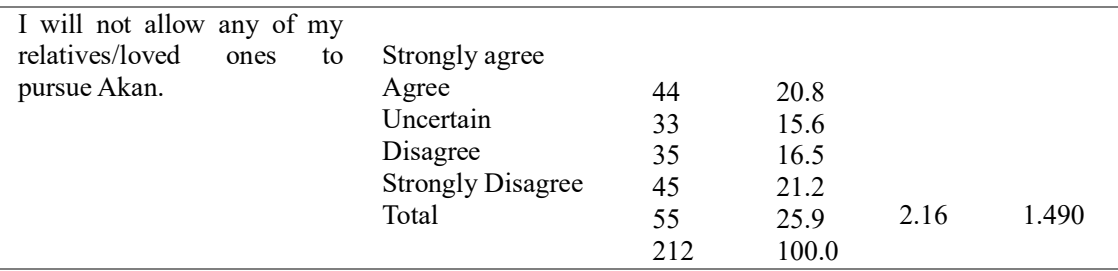

On the statement 'I will not allow any of my relatives to pursue Akan in the future,' (47.1\%), 25.9 strongly agree, and $21.2 \%$ agreed with the statement. It is interesting to note that $(36.4 \%)$, of whom $20.8 \%$ of the participant strongly agreed and $15.6 \%$ agreed to the statement. Yet, another $16.5 \%$ remained uncertain.

\section{Discussion}

The present results study aimed at exploring the participant's attitude forwards the study of Akan at the tertiary level (colleges of education). The study indicates that the participants have a better positive attitude for the study of Akan as a course at the colleges of education and a program of study. The findings concurred with Getie (2020) attitude. Neither negative nor positive would impact language. Therefore, we deduced that since student teachers have a positive attitude towards the study of Akan, it will go a long way to impact their academic endeavors positively. This is supported by Kadodo et al. (2012) that learners with a positive attitude will intrinsically be motivated to invest reasonable time and resources to

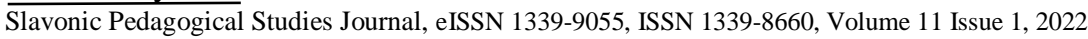


progress steadily towards the target language.

When comparing students' attitudes towards the study of Ghanaian language in general, the findings indicated that participants' attitude was positive because they considered Ghanaian language (Akan) the most interesting course in the college of education. Although participants with other courses are taught in Akan, they do not consider it an easy subject/course as perceived by other students and lecturers and that they equally invest time to study it as they do with other subjects.

On the notion that participants pursue Akan because they are weak students, a strong majority, $73.3 \%$, disagreed. This opposes the view held by other lecturers and students (Bamgbose, 1991; Guerini, 2008; Owu-Ewie $\&$ Edu-Buandoh, 2014). They further affirmed that they have not regretted selecting Akan as a major program in the College of Education. Furthermore, the participants are self-motivated, and they are not afraid to let their friends and other people know they are majoring in Akan at the College of Education. The overwhelming majority indicated that they have not regretted pursuing Akan at the College of Education is an important message signaling educators and policy-makers in Ghana's educational sector.

Lastly, despite the students having a positive attitude toward Akan as a course, a slim majority were positive about permitting their loved ones/relatives to pursue Akan in the future. The remaining seemed to be skeptical about allowing their loved ones to pursue it in the future; over $50 \%$ of the participants, of whom $21.2 \%$ disagreed and $25.9 \%$, strongly disagreed with the remaining $16.5 \%$ uncertain about the statement. This might not be good news for the future of Akan major. If those are pursuing it and those not willing to allow their wards or loved ones to pursue it as expected $\mathrm{t}$, we wonder what those who push the stigma would do. Therefore, it is important to support such students to promote the study of the indigenous languages in Ghana.

\section{Conclusion and implications}

The study of indigenous languages has been accorded negative attitudes and subsequently relegated to the background. The perception about the teaching and learning of the Ghanaian language at the various level of Ghana's educational system is glaring. Lecturers, teachers, and students look down and perceive students majoring in Ghanaian languages as academically weak. As a result, students who major in the Ghanaian languages are stigmatized. The present study investigates the attitude of the student teachers majoring in Akan (the dominant indigenous language) in Ghanaian. This was because they are the ones who are affected by the stigmatization. The study focused on the attitude of the student teachers towards the study of Akan in a subject or course at the Colleges of Education in Ghana and their attitude towards Akan as a program of study. The finding indicated that a strong majority of the participants have a positive attitude towards the study of Akan in the Colleges of Educations. Finally, the study also demonstrated that student teachers majoring in Akan have a positive attitude toward the program, as an 
overwhelming majority of the participant indicated. This indicates that they are not perturbed by the stigma associated with the study of Akan at the tertiary level. However, the participant held diverse opinions to allow their relatives to pursue it at the College of Education.

We believe that all hope is not lost for studying indigenous languages in Ghana, looking at the attitudes of student teachers pursuing Akan at education colleges. It is hoped that this study will inform policymakers in Ghana's educational sector and the government to put the right measures to make the study of the indigenous Ghanaian languages attractive to students, especially those at the tertiary levels.

This study looking at students majoring in Akan was limited to students in three education colleges. We suggest that future studies in this area should look at students who are also pursuing Akan at traditional universities and students who offer other programs at the tertiary levels. Finally, open-ended questionnaires should be mixed with the closed ones to ascertain participants' motivations for the responses in future studies.

\section{Bibliographic references}

Aboagye Da-Costa, C., \& Adade-Yeboah, A. (2019). Language Practice and the Dilemma of a National Language Policy in Ghana: The Past, Present, and Future. International Journal of Humanities and Social Science. 9(3), 142-149.

Adegbija, E. (1994). Language attitudes in Sub-Saharan Africa: A sociolinguistic overview. Africa. Edinburgh: Edinburgh University Press for the International African Institute.

Agyekum K. (2020). Akan cultural concepts and expressions for "stress," "distress," "sorrow," and depression."' Nordic Journal of African Studies 29(3): 1-21

Ajzen, I., \& Fishbein, M. (2000). Attitudes and the attitude-behaviour relation: Reasoned and automatic processes. European review of social psychology, 11(1), 1-33.

Al Alili, S., \& Hassan, W. (2017). Attitudes of Arabic and non-Arabic speaking parents toward the importance of learning Arabic in the United States. Journal of the National Council of Less Commonly Taught Languages, 21(1), 1-36.

Albaugh, E. A. (2014). State-building and multilingual education in Africa. Cambridge University Taught Languages, 21(1), 1-36.

Allport, G. W. (1935). Attitudes. In C. Murchison (Ed.). A handbook of social psychology.

Amissah, P., Andoh-Kumi, K., Asare-Amoah, S., Awedoba, A., Mensah, F., Wilmot, E., \& Miske, S. (2001). IEQ2/Ghana Final report: The implementation of Ghana's school language policy. America Institute for Research.

Andoh-Kumi, K. (1997) Language Education Policies in Ghana. Accra: CRiGLE. 
Armijos Monar, J. G., Fuertes Lopez, B. N., Delgado Altamirano, J. E., \& Villa, V. M. V. (2018). University Indigenous Students' Perceptions towards Kichwa, Spanish and English. English Language Teaching, 11(2), 131-148.

Aydin, H \& Dogan, F. (2019) Journal of Educational Research and Practice 2019, Volume 9, Issue 1, Pages 202-223.

Baker, C. (1992). Attitudes and language. Bristol, PA: Multilingual Matters Ltd.

Bamgbose, A. (1991). Language and the nation: The language question in sub-Saharan Africa. Edinburgh University Press.

Bartram, B. (2010). Attitudes to language, insights from comparative education.

London: Continuum.

Bohner, G. and M. Wanke, (2002). Attitudes and Attitude Change. Hove: Psychology Press. Cleveland: Multilingual Matters.

Edu-Buandoh, D. F. (2006). Multilingualism in Ghana: An ethnographic study of college students at the University of Cape Coast. Unpublished doctoral dissertation. University of Iowa, Iowa, USA.

Edwards. J. (1994). Multilingualism. London: Routledge.

Fishbein, M. and I. Ajzen. (1975). Belief, Attitudes, Intentions, and Behaviour: an introduction to theory and research. MA: Addison Wesley.

Gardner, R. C., Lalonde, R. N., \& Moorcroft, R. (1985). The role of attitudes and

motivation in second language learning: Correlational and experimental considerations. Language learning, 35(2), 207-227.

Gardner, C. R., \& Lambert, E. W. (1972). Attitudes and motivation in second language learning. Newbury House Publishers.

Gardner, R., \& Lambert, W. (1972). Attitudes and motivation in secondlanguage

learning. Rowley, MA: Newbury House.

Getie, A. S. (2020). Factors affecting the attitudes of students towards learning English as a foreign language. Cogent Education, 7(1), 1738184.

Gok, T. and I. Silay. (2010). The effects of problem-solving strategies on students'

achievement, attitude, and motivation. Latin-American Journal of Physics Education 4(1), 7- 21.

Guerini, F. (2008). Multilingualism and language attitudes in Ghana: A preliminary survey. ETHNOREMA Lingue, Popolie Culture 4(4), 1-27.

Heugh, K. (2000). The case against bilingual and multilingual education in South Africa (Vol. 3). Cape Town: Praesa.

Kadodo, W., Mavies, K., Timothy, B., \& Cordial, B. (2012). The influence of teachers and students language attitudes towards the use of shona as a medium of instruction in secondary schools. International Journal of English and Literature, 3(2), 32-39.

Kadodo, W., \& Muzira, A. (2019). The influence of language users' attitudes towards learning and teaching the English language in three postindependence Namibian schools. Journal for Studies in Humanities and Social Sciences, 120-135. 
Khejeri, M. (2014). Language Promotion: Challenges and Solutions International Journal of Humanities and Social Science. 4(1), 32-42.

Kretzer. M (2016) Variations of overt and covert language practices of educators in the North West Province: Case study of the use of Setswana and Sesotho at primary and secondary schools, South African Journal of African Languages, 36(1), 15-24,

Kwofie, R. J. (2001). A pilot study of language attitudes among University of Cape Coast students. Unpublished long essay. University of Cape Coast, Cape Coast.

Larson-Hall, J. (2016). A Guide to Doing Statistics in Second Language Research Using SPSS and R. New York: Routledge.

McLeod, S. (2014). Simply Psychology. Retrieved from Simply Psychology.

Michou, A., Mouratidis, A., Ersoy, E., \& Uğur, H. (2016). Social achievement goals need satisfaction and coping among adolescents. Personality and Individual Differences, 99, 260-265.

Navarro-Villarroel, C. (2011). Young students' attitudes toward languages. Iowa State University.

Omoniyi, T. (2013). Indigenous language capital and development. International

Journal of the Sociology of Language 225: 7-28.

Owu-Ewie, C., \& Edu-Buandoh, D. F. (2014). Living with negative attitudes towards the study of L1 in Ghanaian Senior High Schools (SHS). Ghana Journal of Linguistics, 3(2), 1-25.

Owu-Ewie, C. (2007). The language policy of education in Ghana: constraints and the way forward. Journal of the African Language Teachers Association 9 (2): 1-40.

Owu-Ewie, C. (2019). Introduction to Language Teaching: A resource for Language Teachers. Accra: Shine Prints Company Ltd.

Ramachandran, R., \& Rauh, C. (2016). Discriminatory attitudes and indigenous

language promotion:Challenges and solutions (No. 2016/78). WIDER Working Paper.

Salta, K. \& Tzougraki, C. (2004). Attitudes towards chemistry among 11thgrade

students in High Schools in Greece. Science Education 88, 353-547.

Sarfo, E. (2012). Ghanaian university students' attitudes towards English. International Review of Social Sciences and Humanities 4(1): 86-99.

Sanusi, I. O. (2019). The Negative Attitude of Banning Indigenous Nigerian Languages from English Language Classroom: A Linguistic Misconception. Journal of Applied Linguistics and Language Research, 5(6), 129-138.

Sarfo, E. (2012). Ghanaian university students' attitudes towards English. International Review of Social Sciences and Humanities 4(1) 86-99.

Seti V., Bornman, E. \& Mosquera, P. (2015). The International Journal of Communication and Linguistic Studies. 14(1), 20-15. 
Tódor, E. M., \& Degi, Z. (2016). Language Attitudes, Language Learning Experiences and Individual Strategies What Does School Offer and What Does It Lack?. Acta Universitatis Sapientiae, Philologica, 8(2), 123-137. Wamalwa, E. W. (2013) Multilingualism and language attitude: Students perceptions towards Kiswahili in Mtwara region of Tanzania. Research in Humanities and Social Sciences.

Abdulai Akuamah

Department of Languages

St. Joseph's College of Education, Bechem

P.O. Box 15

Ghana

akuamha81@gmail.com

Faustina Gyampoh

Department of Languages

Abetifi Presbyterian College of Education, Abetifi-Kwahu

Ghana

f0206976367g@gmail.com

Leticia Asamoah

Department of Languages

P.O.Box 15

Fosu College of Education, Fosu

Ghana

littasamoah@yahoo.com 